\title{
Effect of the media on morphology of Cryphonectria parasitica (Murr.) Barr isolates and their Vegetative Compatibility Groups
}

\author{
Gabriella Kovács - László Radócz \\ University of Debrecen, Institute of Plant Protection, Debrecen \\ kovacs.gabriella@agr.unideb.hu
}

SUMMARY

\begin{abstract}
The most dangerous pathogen for the European and American chestnuts is the blight fungus Cryphonectria parasitica (Murrill) Barr. Short after its introduction a big number of chestnut trees were destroyed on the infested area. The control could be really complicated, because of the numerous vegetative compatibility groups of the fungus. There is a type that carries a mycovirus viz. hypovirus in the cytoplasm. We are able to control effectively this pathogen by using mycovirus-carrying strains (called hypovirulent fungal strains also). In laboratory it is easy to multiply the virulent and the hypovirulent strains of the fungus but do not easy to differentiate colonies visually on simple PDA medium. During our research, we tested different types of media, based on potato and chestnut bark extract respectively. It was observed that on potato medium the virulent strains produce more orange pigments. So it is more easy to differentiate virulent or hypovirulent isolates of chestnut blight fungus based on colony colour and morphology.
\end{abstract}

Keywords: Cryphonectria parasitica, chestnut blight fungus, different types of media, colony morphology

\section{INTRODUCTION}

The European chestnut (Castanea sativa) belongs to the plant family Fagaceae and it is endemic in Europe and Asia. It has many pathogens and injured by insects, but the most important pathogens were in the last century and even today Phytophtora spp. and Cryphonectria parasitica both in America and Europe as well. At the beginning of the 20th century Cryphonectria parasitica fungus was introduced first in the east coast of the USA (Merkel, 1906), and during the 40 next years it destroyed all American chestnut forests. This means about 4 million hectares of trees (Young et al., 2000). After the appearance of Cryphonectria parasitica in Europe it spread rapidly across the continent. While the fungus arrived to Italy from the USA (Biraghi, 1946), but the forests in France were infected by the fungus introduced directly from Asia. The chestnut blight fungus in Asia evolve together with the host trees (coevolution), so these tree species have got some tolerance to the fungus. That's why symptoms of Cryphonectria parasitica hardly visible on the infected Asian chestnut trees. During the sexual reproduction of the fungus many Vegetative Compatibility Groups (VCGs) could appear. So the disease control could be more difficult on these places. In Europe there are more than 65 VCGs (Heiniger, 1994). There is another form of the Cryphonectria parasitica with decreased virulence and called hypovirulent fungus strain. This contains a pathogenic mycovirus in its cytoplasm (Anagnostakis, 1977). By application this hypovirulent strains can be controlled the virulent fungus. While the virulent fungus spread rather fast in a forest, the hypovirulent one extend much slowly.

\section{MATERIALS AND METHODS}

The symptoms on the bark cancer can be various, so we have differentiated „sunking canker”, „opened canker” and „surface canker” (Roane et al., 1986; Radócz, 2010). In case of the opened and sunking cankers we have to identify which vegetative compatibility group belongs to the given fungus. In addition it is need to find the adequate hypovirulent fungus which belongs to the same VCG before starting the effective protection.

The surface canker, also called callused canker refers to the presence of the hypovirulent fungus, however during the recovery process the virulent fungus might occur. If we sampling this part and put on a simple PDA medium it is difficult to differentiate virulent and hypovirulent characteristics. During the VCG identification can not be obviously detect in on the base of hyphae (hyphae anastomosis).

During our tests we looked for such a culture medium, on which the pigmentation of virulent fungus and other morphological characters were clearly distinguishable. We separated our samples during the process to take the above-mentioned canker types into consideration, so probably received virulent and hypovirulent isolates.

The indentification process of the sampling and determination of VCGs are the following:

Taking small pieces from the border of the infected and healthy part of the chestnut bark. The sampler tools (knives, scalpels) were disinfected by $70 \%$ ethanol, and every single sample was put into marked paper bag and stored in fridge. Bark sample surface was sterilized also by $70 \%$ ethanol for 2 minutes and soaked in sterile distilled water for 1 minute just before putting them on the surface of culture medium. After this we incubated the Petri dishes in $24^{\circ} \mathrm{C}$ thermostate for 3 days. Unfortunately it is possible that despite of the disinfection process, pathogens might remain in the bark, that's why multiple isolation is necessary. 
The identification of the vegetative compatibility groups were completed by using EU tester strains. These are available in the Mycological Collection of the Institute of Plant Protection, University of Debrecen. The EU tester strains were propagated in Petri dishes on PDA culture media. Samples from the two media - EU-tester and the and the unidentified sample - were cut $5 \mathrm{~mm}$ cubes and placed close to each other in a new Petri dish. If the two fungus strains were compatible, the hyphae anastomosis was formed and also the transmission of the double-standed RNA might happened.

In the case of hypovirulent fungus the hyphae textures are hardly visible, and it is difficult to evaluate the hyphae anastomosis has happened or not. That's why we tried different culture media enriched by chestnut bark extract.

We took into consideration requirement vitamin for the fungus and the circumstances of natural occurrence moreover our previous experiment results. The biotin was used by several persons previously (Radócz, 1995). Potato dextrose agar (Scharlab, S.L.) was added $1 \mathrm{mg} / \mathrm{l}$ biotin after sterilization (Autoclave AE 150 Dry Raypa).

As in most cases the growth of the fungus on PDA media is appropriate, another culture medium was made from cooked fresh potato, trusting in that the fungal morphological characteristics will be more clearly identifiable. For making 1 liter medium 200gramms of fresh potato was cut, cooked 20 minutes and was filtrated. To the natural medium were added 20g agar-agar (Spektrum 3D) and 20g glucose (Reanal Rt.) per liter as well. The quantity of medium was amended by distilled water to 1 liter and it was sterilized in autoclave.

Another culture medium made from cooked fresh potato was enriched by $1 \mathrm{mg} / \mathrm{l}$ biotin just before pouring into Petri dishes.

Simulating the natural spreading of the fungus, it was attempt to provide ideal circumstainces to growth. Healthy chestnut bark (5g/l) was given to the potato culture medium which guarantees the proper tannin acid amount. In parallel with this, after sterilization $1 \mathrm{mg} /$ liter biotin was also added to ensure the growing criteria.

\section{RESULTS}

Due to the transparent consistence of the media and the hyphae whitish colour, the hyphae textures are hardly visible on PDA and PDA+biotin media. The pigmentation of the virulent fungus strains started up on the potato medium, so the virulent (orange) and hypovirulent (white) isolates were easy to separate. However, we have not experienced significant differences in the intensity of the growth of the fungus on the media which is enriched by biotin. With the bark addition to the potato the characters of the fungus is more outstanding, and on the surface of darker, containinig bark tannin media, the pigmentation is clearly visible (Figure 1).

Figure 1: Conversions of Pécsbánya hypovirulent + Pálháza virulent isolates on different media
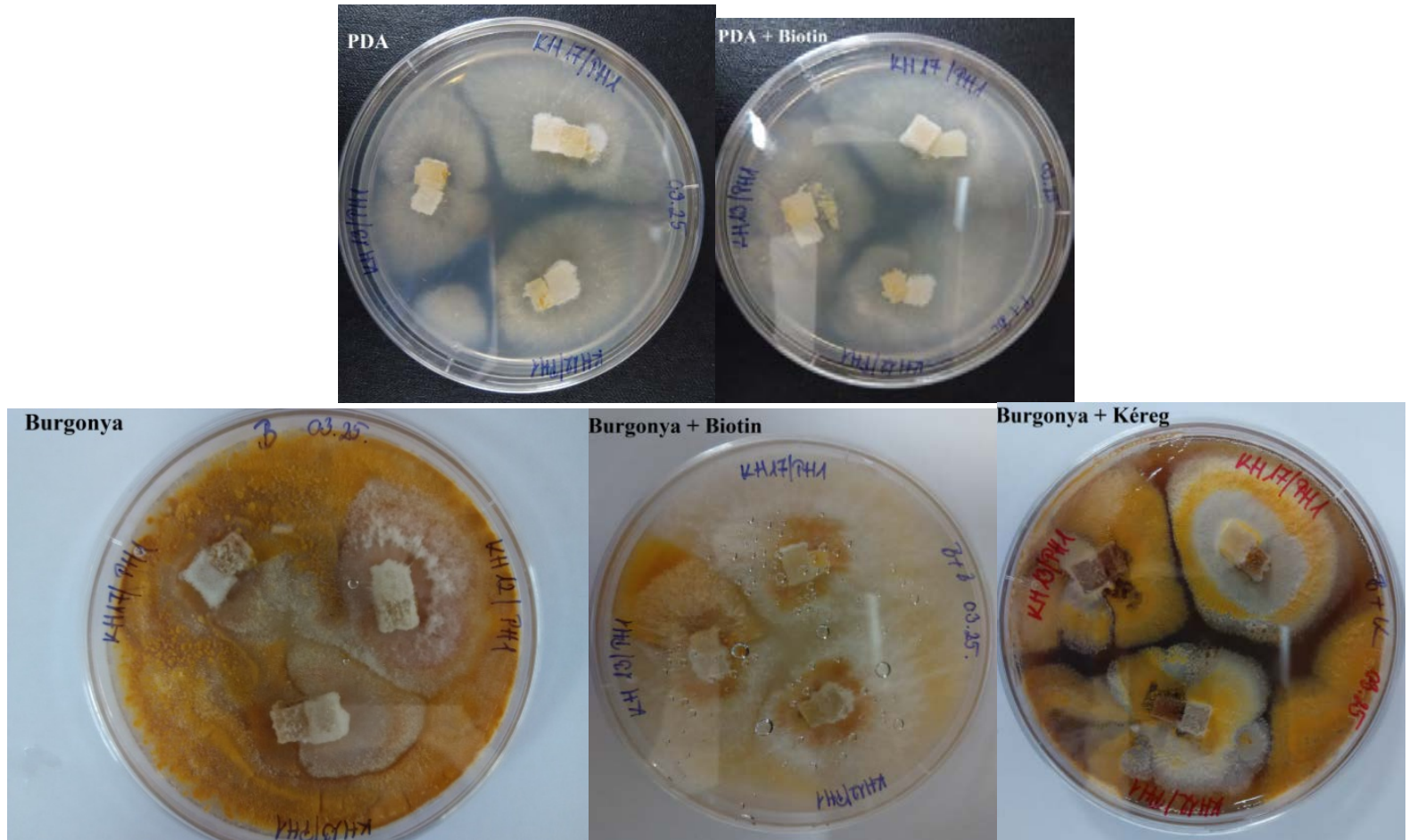

burgonya = fresh potato medium; kéreg = contains chestnut bark 
Testing the media shown clearly that both the measured parameters and visual observation on the potato+biotin+bark type medium resulted slower growing both on virulent and hypovirulent isolates and the mycelium has not grown in concentric rings as usual (Figure 2).

Figure 2: Growing hypovirulent strain from Pécsbánya (NH 11)

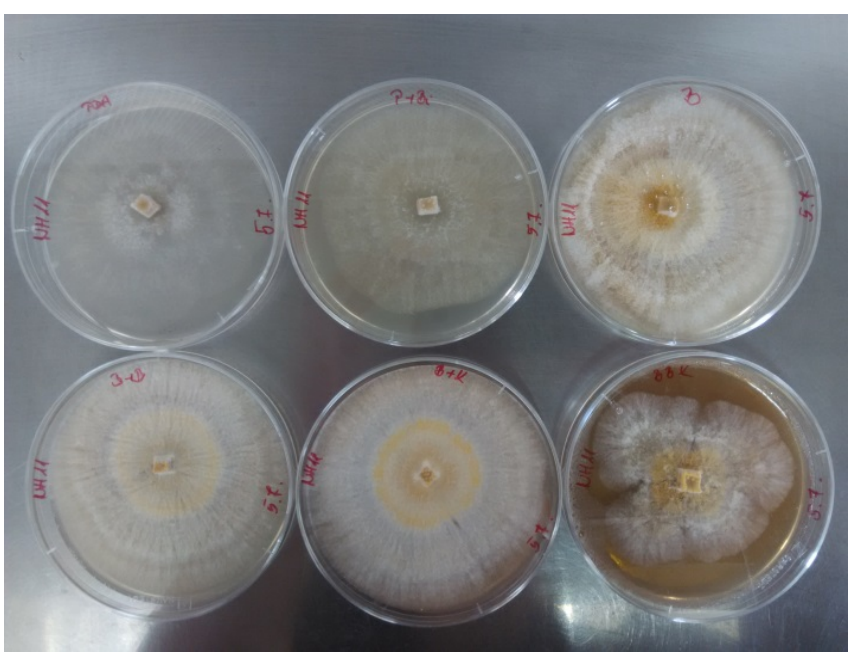

PDA (top left) PDA+Biotin (top middle), fresh potato (top right), fresh potato+biotin (bottom left), fresh potato+bark (bottom middle), fresh potato+biotin+bark ('BBK', bottom right) media

Using the SPSS statistical software was confirmed that the 'BBK' marked media proved the least appropriate for growth monitoring and conversion testing of Cryphonectria parasitica fungus due to the smaller growing intensity (Figure 3).

Figure 3: Average diameter of all analysed fungal strains on different cultural media

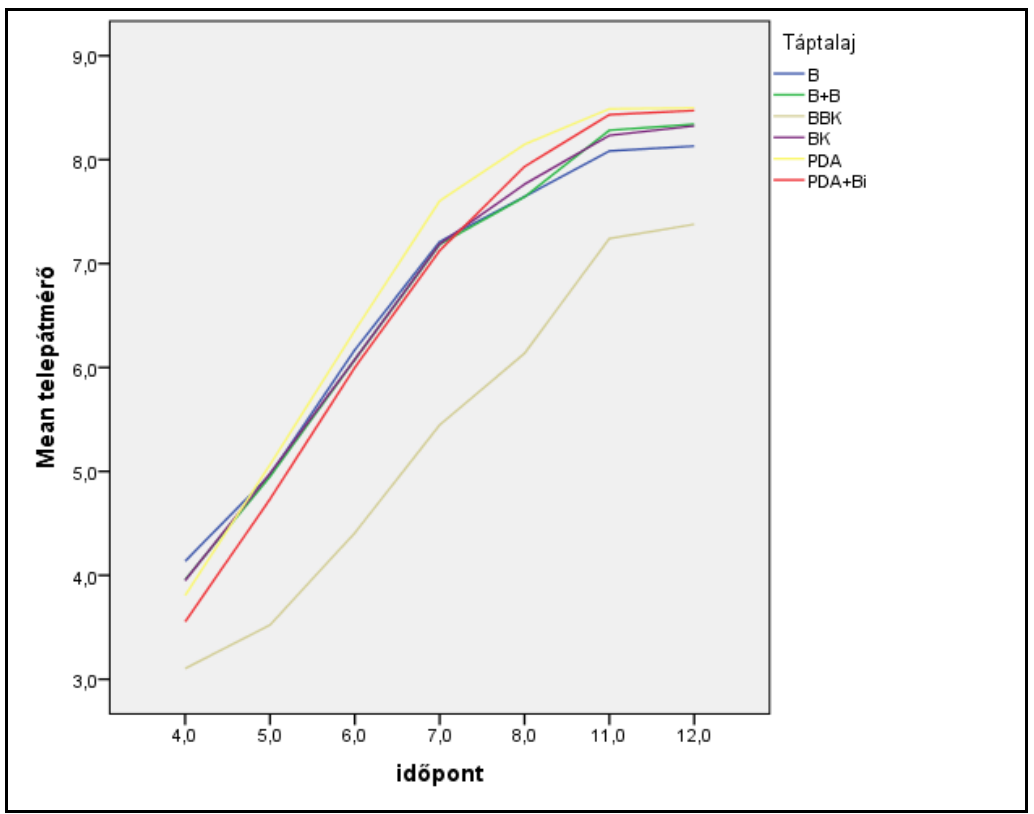

mean telepátmérő $=$ mean colony size in diameter $(\mathrm{cm})$, időpont $=$ time (days), táptalaj $=$ media, $\mathrm{B}=$ fresh potato, $\mathrm{B}+\mathrm{B}=$ fresh potato + biotin, $\mathrm{BK}=$ fresh potato+chestnut bark, $\mathrm{BBK}=$ fresh potato + biotin + chestnut bark, $\mathrm{PDA}=$ potato dextrose agar, $\mathrm{PDA}+\mathrm{Bi}=$ potato dextrose agar + biotin

It seems well on the graphs that the PDA cultural media was the best for growing the Cryphonectria parasitica considering the growing speed on the fifth day, and the PDA+biotin (BDA+Bi) medium on the seventh one. Because shortage of pigmentation fungal attributions are hardly visible.

On potato-based media resulted the same in all cases without significant differences (Figure 4). 
Figure 4: Average fungal colony in diameter and standard deviations

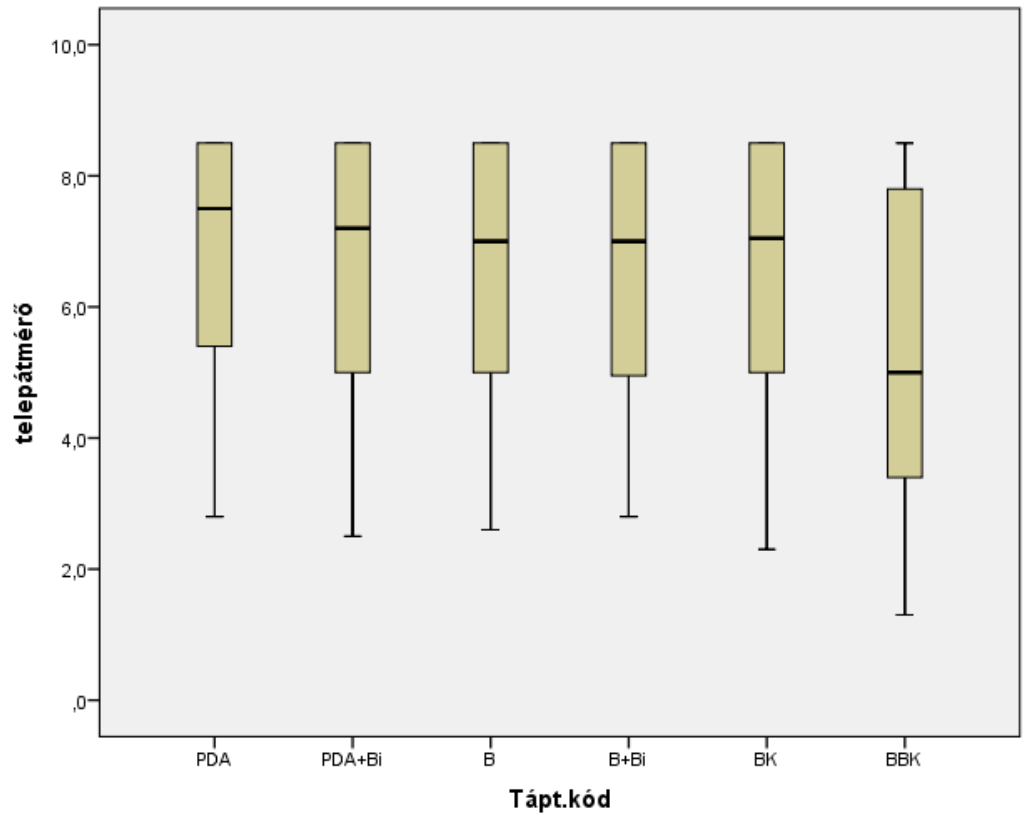

telepátmérő $=$ mean colony size in diameter $(\mathrm{cm})$, tápt.kód $=$ media, $\mathrm{PDA}=$ potato dextrose agar, $\mathrm{PDA}+\mathrm{Bi}=$ potato dextrose agar + biotin, $\mathrm{B}$ $=$ fresh potato, $\mathrm{B}+\mathrm{Bi}=$ fresh potato + biotin, $\mathrm{BK}=$ fresh potato + chestnut bark, $\mathrm{BBK}=$ fresh potato + biotin+chestnut bark

On the Figure 5 the pigmentation of the virulent fungus is visible on the fresh potato media in contrast with PDA, where the mycelium is rather white. The PDA + biotin is transparent, but in the fresh potato based medium the pigmentation is clearly visible. On the fresh potato based + biotin is also sensible, and the fluffy mycelium seems somewhat more. In the middle there is the potato based and bark added cultural media, and due to its dark colour, the fungal colony is more noticeable. Biotin was added to the media on the last Petri dish as we expounded before. The fungal characteristics are clearly showed, but the fungal development was slower. However the fan-form mycelium which was described in various studies can be observed on this media clearly.

Figure 5: Virulent isolate from Pécsbánya (NV 8)

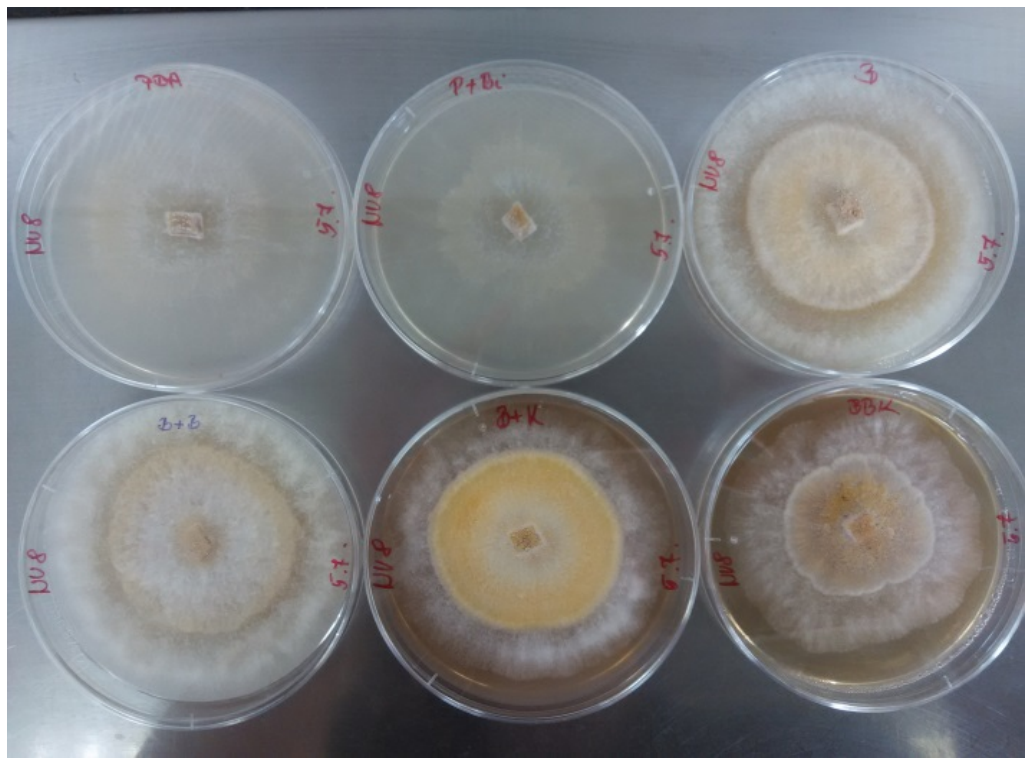

PDA (top left), PDA + biotin (top middle), fresh potato based (top right), fresh potato based + biotin (bottom left), fresh potato based + chestnut bark (bottom middle), fresh potato based + biotin + chestnut bark (bottom right) 


\section{CONCLUSIONS}

Overall we stated that the biotin supply of media seems unnecessary because it did not resulted any advanatage in growth of the chestnut blight fungal isolates. By the coupling of virulent and hypovirulent strains on PDA medium did not result obvious, clearly visible reaction to check visible the efficacy of conversions or hyphae anastomoses.

It seems reasonable to use fresh potato based + chestnut bark medium to cultivate Cryphonectria parasitica isolates during conversion tests of hypovirulent and virulent strains.

\section{REFERENCES}

Anagnostakis, S.L. (1977): Vegetative incompatibility in Endothinia parasitica. Exp. Mycol. 1: 306-316.

Anagnostakis, S.L. (1987): Chestnut blight: The classical problem of an introduced pathogen. Mycology 79: 23-37.

Anagnostakis, S.L. (1993): Valuable chestnut germplasm in Connecticut. Annual Report of the Northern Nut Growers Association 83: 53-54. Biraghi, A. 1(946): Il cranco del castagno causato da Endothinia parasitica. Agric.Ital. 7: 1-9.

Biraghi, A. (1950): Caratteri di resistence in Castanea sativa nei confronti de Endothinia parasitica. Boll. Stn.Patol.Veg., Rome. 7: $161-171$.

Heiniger, U. - Rigling, D. (1994): Biological control of chestnut blight in Europe. Annual Review of Phytopathology 32: 581-599.

Merkel, H.W. (1906): A deadly fungus ont he American chestnut. N.Y.Zool.Soc.Am. Rep.10: 204-210.

Radócz L. (2010): A Nagymarosi szelídgesztenyések története, ápolása, védelme. Debreceni Egyetem Kiadó. 83 pp.

Radócz L. (2014): Az európai szelídgesztenye szaporítása, ápolása, védelme. University Press Debrecen. 165 pp.

Roane, M.K. - Griffin, G.J. - Elkins, J.R. (1986): Chestnut blight, other Endothia diseases, and the genus Endothia. The American Phytopathological Society, St. Paul, Minnesota, USA. 53 pp. 